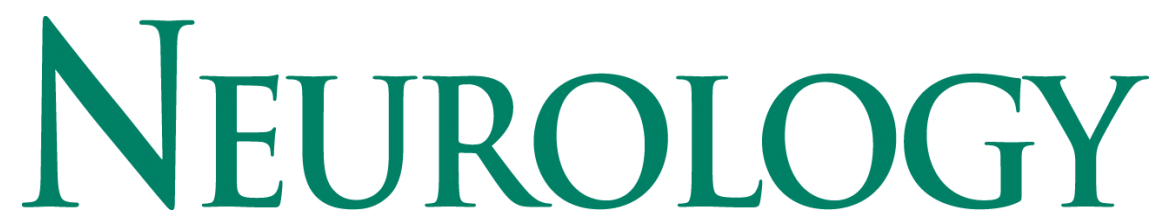

Reduced brain choline in homocystinuria due to remethylation defects

F. -G. Debray, Y. Boulanger, A. Khiat, J. -C. Decarie, J. Orquin, M. -S. Roy, A. Lortie,

F. Ramos, N. M. Verhoeven, E. Struys, H. J. Blom, C. Jakobs, E. Levy, G. A. Mitchell and M. Lambert

Neurology 2008;71;44-49

DOI: 10.1212/01.wnl.0000316391.40236.c3

This information is current as of January 30, 2009

The online version of this article, along with updated information and services, is located on the World Wide Web at:

http://www.neurology.org/cgi/content/full/71/1/44

Neurology ${ }^{\circledR}$ is the official journal of the American Academy of Neurology. Published continuously since 1951, it is now a weekly with 48 issues per year. Copyright $\left({ }^{\circ} 2008\right.$ by AAN Enterprises, Inc. All rights reserved. Print ISSN: 0028-3878. Online ISSN: 1526-632X.

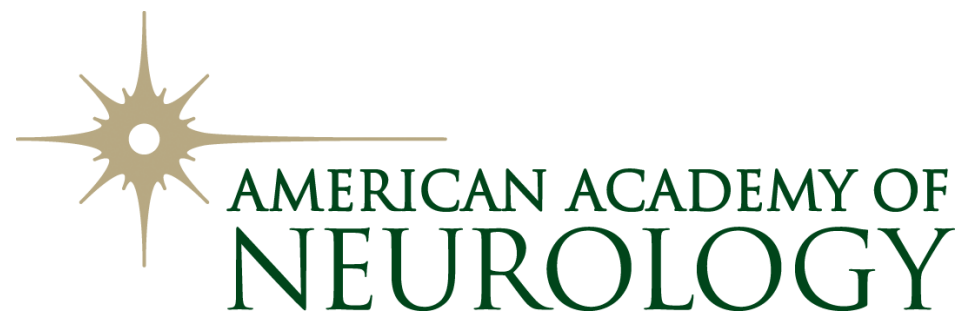


F.-G. Debray, MD

Y. Boulanger, $\mathrm{PhD}$

A. Khiat, $\mathrm{PhD}$

J.-C. Decarie, MD

J. Orquin, MD

M.-S. Roy, PhD

A. Lortie, MD

F. Ramos, MSc

N.M. Verhoeven, PhD

E. Struys, $\mathrm{PhD}$

H.J. Blom, PhD

C. Jakobs, PhD

E. Levy, MD, PhD

G.A. Mitchell, MD

M. Lambert, MD

Address correspondence and reprint requests to Dr. Marie Lambert, Division of Medical Genetics, Ste-Justine Hospital, 3175 Côte-Sainte-Catherine, Montreal, Quebec, H3T 1C5,

Canada

marie.lambert@umontreal.ca

Supplemental data at www.neurology.org

\section{Reduced brain choline in homocystinuria due to remethylation defects}

ABSTRACT

Objective: To investigate whether secondary impairment of the transmethylation pathway is a mechanism underlying the neurologic involvement in homocystinuria due to remethylation defects.

Methods: Twelve patients with neurologic disease due to remethylation defects were examined by brain magnetic resonance spectroscopic imaging $\left({ }^{1} \mathrm{H}\right.$ MRSI). Brain $\mathrm{N}$-acetylaspartate, cholinecontaining compounds (Cho), and creatine ( $\mathrm{Cr}$ ) were quantified and compared to with controls. Metabolites of remethylation cycle and creatine biosynthesis pathway were measured in plasma and urine.

Results: MRSI revealed isolated Cho deficiency in all regions examined (mean concentration units $\pm S D$, patients vs controls): frontal white matter (0.051 \pm 0.010 vs $0.064 \pm 0.010 ; p=0.001)$, lenticular nucleus $(0.056 \pm 0.011$ vs $0.069 \pm 0.009 ; p<0.001)$, and thalamus $(0.063 \pm 0.010$ vs $0.071 \pm 0.007 ; \mathrm{p}=0.006)$. In contrast to controls, the $\mathrm{Cho} / \mathrm{Cr}$ ratio decreased with age in patients in the three brain regions examined. Low creatine urinary excretion $(p<0.005)$, normal urine and plasma guanidinoacetate, and a paradoxical increase in plasma S-adenosylmethionine $(p<0.005)$ concentrations were observed.

Conclusion: Patients with homocystinuria due to remethylation defects have an isolated brain choline deficiency, probably secondary to depletion of labile methyl groups produced by the transmethylation pathway. Although biochemical studies suggest mild peripheral creatine deficiency, brain creatine is in the reference range, indicating a possible compartmentation phenomenon. Paradoxical increase of S-adenosylmethionine suggests that secondary inhibition of methylases contributes to the transmethylation defect in these conditions. Neurology ${ }^{\circledR} 2008 ; 71: 44-49$

\section{GLOSSARY}

CbIC = combined homocystinuria-methylmalonic aciduria; CbIG = methionine synthase deficiency; CBS $=$ cystathionine $\beta$-synthase; $\mathbf{C h o}=$ water-soluble choline-containing compounds; $\mathbf{C r}=$ creatine; $\mathbf{D Q}=$ developmental quotient; Met = plasma methionine; $\mathbf{M R}=$ magnetic resonance; $\mathbf{M S R I}=$ magnetic resonance spectroscopic imaging; $\mathbf{M T H F R}=$ methylene tetrahydrofolate reductase; $\mathbf{N A}$ = not available; $\mathbf{N A A}=\mathrm{N}$-acetylaspartate; $\mathbf{N N}=$ neonatal; $\mathbf{N S}$ = not significant; $\mathbf{O A}=$ optic atrophy; OMA = oculomotor apraxia; OMIM = Online Mendelian Inheritance in Man; PM = pigmentary maculopathy; $\mathbf{P t}=$ patient; $\mathbf{R D}=$ remethylation defect; $\mathbf{R P}=$ retinitis pigmentosa; $\mathbf{t H c y}=$ plasma total homocysteine; $\mathbf{T H F}=$ tetrahydrofolate.

Homocystinuria due to remethylation defects $(\mathrm{RD})$ is a group of inherited metabolic diseases characterized by chronic and progressive neurologic impairement. ${ }^{1}$ In contrast to homocystinuria due to cystathionine $\beta$-synthase (CBS) deficiency, plasma methionine concentration is low in $\mathrm{RD}$, and there is neither skeletal involvement nor ectopia lentis. Despite treatments effective in reducing plasma homocysteine level, the neurologic outcome in RD is often poor. ${ }^{2,3}$

From a metabolic point of view, the methionine-homocysteine cycle is a carrier of activated methyl group taking part in the transmethylation pathway (figure 1). ${ }^{1}$ Labile methyl groups are provided by dietary methionine, glycine, serine, betaine, and choline. They are also produced endogenously through the folate cycle by methylenetetrahydrofolate reductase (MTHFR) in the form of 5 ' methyltetrahydrofolate (figure 1, step A), and transferred to homocysteine to produce methionine (step B). This last step is formally called remethylation pathway. The activated form of methionine, $S$-adenosylmethionine (AdoMet), is the methyl donor for many important biosynthetic

\footnotetext{
From the Divisions of Medical Genetics (F.-G.D., G.A.M., M.L.) and Neurology (A.L.), Department of Pediatrics; Departments of Medical Imaging (J.-C.D.), Ophthalmology (J.O., M.-S.R.), Psychology (F.R.), and Nutrition (E.L.), University of Montreal and Ste-Justine Hospital, Montreal, Quebec, Canada; Department of Radiology (Y.B., A.K.), University of Montreal and Hôpital Saint-Luc, Montreal, Quebec, Canada; and Metabolic Unit (N.M.V., E.S., H.J.B., C.J.), Department of Clinical Chemistry, VU University Medical Center, Amsterdam, The Netherlands. Disclosure: The authors report no disclosures.
} 


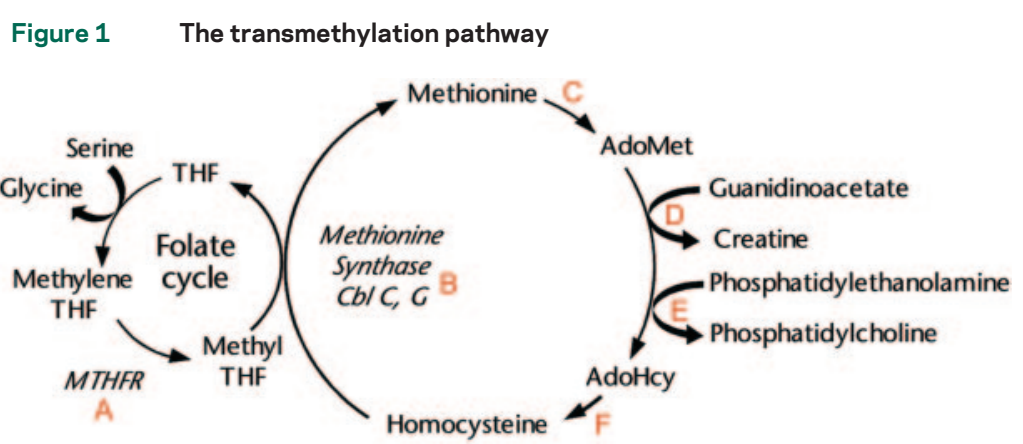

Labile methyl groups flux nation performed for assessment of various nonmetabolic neurologic disorders. Individuals with unexplained encephalopathy diffuse cerebral abnormalities and those who received brain irradiation were excluded. Informed consent was obtained from participants or their legal guardians, and the Institutional Review Board of Ste-Justine Hospital approved the study.

Brain MRI and spectroscopy. Patients and controls underwent brain MRI and ${ }^{1} \mathrm{H}$ MRSI examinations on a 1.5-tesla Magnetom Symphony MR imager (Siemens, Erlangen, Germany) using a standard circularly polarized head coil. MRSI data were acquired with the point-resolved spectroscopy sequence on a 15mm-thick axial slice passing through the center of the thalami. Acquisition parameters were a field of view of $16 \times 16 \mathrm{~cm}^{2}$, a voxel size of $15 \times 10 \times 10 \mathrm{~mm}^{3}, 16$ phase-encoding steps in each direction, an echo time of $135 \mathrm{~ms}$, and a repetition time of 1,500 ms. Quantitation of the metabolite signals of $N$-acetylaspartate (NAA), creatine plus phosphocreatine (Cr), and choline-containing compounds (Cho), as well as the Cho/Cr ratio, was performed using the LCModel software package. ${ }^{8} \mathrm{Me}-$ tabolites levels were quantitated from a single voxel in each hemisphere for three brain areas: thalamus, frontal white matter, and lenticular nucleus. For each individual, the concentration for a specific brain area was the mean of the left and right sides measurements. Metabolite units were the untransformed concentrations as recorded by LCModel.

processes. ${ }^{4}$ Quantitatively and qualitatively, the most important methyl consumers are creatine, phosphatidylcholine, and sphingomyelin biosynthesis, as well as DNA methylation. ${ }^{4,5}$

Overall, this suggests that the pathophysiologic mechanisms underlying neurologic impairment may be distinct between RD and CBS deficiency. In contrast to CBS deficiency, low methionine levels in RD can impair the transmethylation pathway (figure 1), potentially contributing to the neurologic involvement. To test this hypothesis in vivo, we investigated a group of patients with RD by magnetic resonance spectroscopic imaging (MRSI) to measure creatine and cholinecontaining compounds in the brains of these patients. The concentrations of the metabolites of transmethylation pathways were also determined in plasma and urine.

METHODS Patients and controls. Twelve patients (median age 6 years, range 2-22 years) with homocystinuria due to $\mathrm{RD}$ were prospectively included: seven patients with combined homocystinuria-methylmalonic aciduria (CblC, Online Mendelian Inheritance in Man [OMIM] no. 277400), one patient with methionine synthase deficiency (CblG, OMIM no. 250940), and four patients (including three siblings, patients 9-11) with MTHFR deficiency (OMIM no. 236250). Diagnoses were confirmed by enzyme assays (MTHFR), complementation studies ( $\mathrm{CblC}$ and $\mathrm{G})$, and molecular analyses ( $\mathrm{CblC})$ as previously described $^{6,7}$ (performed by Dr. D.S. Rosenblatt, McGill University, Montreal, Canada). Patients' medical charts were retrospectively reviewed. Controls included 36 consecutive children of similar age (median 6.9 years, range 2-18 years) for whom magnetic resonance (MR) spectra were acquired after a brain MRI exami-
Biochemical studies. Venous blood was collected in a 15$\mathrm{U} / \mathrm{mL}$ sodium heparin tube and placed on ice. Samples were centrifuged immediately and plasma stored at $-80^{\circ} \mathrm{C}$. Before storage at $-80^{\circ} \mathrm{C}$, an aliquot of plasma was deproteinized with perchloric acid for determination of AdoMet and S-adenosylhomocysteine (AdoHcy). Plasma amino acid concentrations were measured by automated ion-exchange chromatography (Biochrom 30, Fisher Scientific Ltd.) and plasma total homocysteine by fluorescence polarization immunoassay (IMx homocysteine kit, Abbott). Plasma AdoMet and AdoHcy concentrations were determined using stable isotope dilution tandem mass spectrometry. ${ }^{9}$ Guanidinoacetate and creatine were measured in plasma and urine using stable isotope dilution gas chromatography-mass spectrometry as previously reported. ${ }^{10,11}$

Statistical analyses. Brain metabolites measured by MRSI were compared between patients and controls using a Student $t$ test. Linear regression was used to examine the association between age (explanatory variable) and brain metabolite concentrations and ratios (dependent variable) in patients and controls. To test whether the magnitude of the effect of age on metabolite concentrations and ratio varied as a function of the diagnostic category (patients vs controls), we used a product term (age * diagnostic category; controls $=$ reference group). The regression coefficient of the product term (age * diagnostic category) can be interpreted as the amount of change in the association between age and brain metabolites when diagnostic category is "patients" instead of "controls" (reference category). A one-sample signed rank test was used to compare patients' plasma and urine metabolite concentrations and the upper limit of the given reference range for homocysteine, AdoMet, AdoHcy, guanidinoacetate, and the lower limit of the given reference range for methionine and creatine. The $95 \% \mathrm{CI}$ of the proportion of patients with plasma or urine concentrations of transmethylation and creatine biosynthesis pathways above (or below) the upper (or lower) limit of the reference range were estimated as previously described. ${ }^{12}$ Reference ranges for each of these plasma and urine metabolites were provided by the laboratory that performed the 
Table $1 \quad$ Characteristics of patients

\begin{tabular}{|c|c|c|c|c|c|c|c|c|}
\hline \multirow[b]{2}{*}{$\mathrm{Pt}$} & \multicolumn{3}{|c|}{ Initial presentation } & \multicolumn{4}{|c|}{ Current status } & \multirow[b]{2}{*}{ Diagnosis } \\
\hline & $\begin{array}{l}\text { Age, } \\
\text { mo }\end{array}$ & Symptoms & $\begin{array}{l}\mathrm{tHcy} / \mathrm{Met} \\
\mu \mathrm{mol} / \mathrm{L}^{*}\end{array}$ & $\begin{array}{l}\text { Age, } \\
y\end{array}$ & Seizure & $\begin{array}{l}\text { Cognitive } \\
\text { status }^{+}\end{array}$ & Ophthalmology & \\
\hline 1 & 2 & Poor feeding & $\mathrm{NA} / 13$ & 22 & - & $77(\mathrm{IQ})$ & $\mathrm{PM}, \mathrm{RP}$ & Cblc \\
\hline 2 & 4 & Seizures, lethargy & $50 / 3$ & 6 & + & $87(\mathrm{IQ})$ & Normal & CblG \\
\hline 3 & 1 & Lethargy, poor feeding, hypothermia & $186 / 23$ & 5 & - & $58(\mathrm{IQ})$ & $\mathrm{PM}, \mathrm{RP}, \mathrm{OA}$ & Cblc \\
\hline 4 & 1 & Developmental delay (NN screening) & $\mathrm{NA} / 5$ & 18 & - & $62(\mathrm{IQ})$ & PM & Cblc \\
\hline 5 & 1 & Seizures, lethargy, hypotonia & $166 / 13$ & 6 & - & $55(\mathrm{DQ})$ & $\mathrm{OA}$ & Cblc \\
\hline 6 & 1 & None (NN screening) & $234 /<5$ & 2 & - & $63(\mathrm{DQ})$ & PM & $\mathrm{CblC}$ \\
\hline 7 & 1 & Lethargy, poor feeding & $188 / 4$ & 4 & - & 67 (IQ) & $\mathrm{PM}, \mathrm{RP}, \mathrm{OA}$ & $\mathrm{CblC}$ \\
\hline 8 & 2 & Seizures, nystagmus, megaloblastosis & $60 / N A$ & 7 & + & $20(\mathrm{DQ})$ & $\mathrm{PM}, \mathrm{RP}, \mathrm{OA}$ & Cblc \\
\hline 9 & 11 & Developmental delay & $137 / 8$ & 3 & + & $22(\mathrm{DQ})$ & OMA & MTHFR \\
\hline 10 & 142 & Seizures, mental retardation & $176 / 12$ & 13 & + & $53(\mathrm{IQ})$ & Normal & MTHFR \\
\hline 11 & 131 & Mental retardation & $131 / 11$ & 11 & - & 68 (IQ) & Normal & MTHFR \\
\hline 12 & 9 & Encephalopathy, seizures, microcephaly & $194 / 7$ & 6 & + & $22(\mathrm{DQ})$ & Normal & MTHFR \\
\hline
\end{tabular}

*Normal values for plasma total homocysteine (tHcy), 5-15 $\mu \mathrm{mol} / \mathrm{L}$; and for plasma methionine (Met), 9-37 $\mu \mathrm{mol} / \mathrm{L}$. 'Neuropsychological testing included evaluation of IQ by the Wechsler Adult Intelligence Scale-Revised, the Wechsler Intelligence Scale for Children Version III, and the Leiter, and assessment of developmental quotient (DQ) by the Griffiths Mental Development Scale, according to patient's age and developmental status.

$\mathrm{Pt}=$ patient; $\mathrm{NA}=$ not available; $\mathrm{PM}=$ pigmentary maculopathy $\mathrm{RP}=$ retinitis pigmentosa; $\mathrm{CbIC}=$ combined homocystinuria-methylmalonic aciduria; $\mathrm{CbIG}=$ methionine synthase deficiency; $\mathrm{OA}=$ optic atrophy; $\mathrm{NN}=$ neonatal; $\mathrm{OMA}=$ oculomotor apraxia; MTHFR = methylene tetrahydrofolate reductase deficiency.

biochemical measurement; thus, the reference populations for these measurements were different from the controls for the MRSI studies. Only unrelated patients were included in statistical analyses to avoid overrepresentation of the three members of the same family (only the proband was included). Statistical significance was set at $<0.05$. Statistical analyses were performed with SAS statistical software (version 9.1, SAS Institute, Inc., Cary, NC).

RESULTS Characteristics at presentation and current status of patients are shown in table 1. Median age at diagnosis was 2 months (range 1-142 months). Ten patients had low methionine concentration $(<14 \mathrm{mmol} / \mathrm{L})$ at diagnosis. Patients were initially treated with hydroxocobalamin (IM injections), folic acid, betaine, and moderate protein restriction. CblC patients received oral L-carnitine supplementation. Hydroxocobalamin was discontinued in MTHFR patients. No CblC patient experienced episode of acidosis after initiation of treatment. Currently, no patient has signs of spasticity.

Brain MRI. Results of brain MRI are summarized in table e-1 on the Neurology ${ }^{\circledR}$ Web site at www. neurology.org. The main neuroradiologic findings were nonspecific cerebral atrophy with periventricular white matter loss. For many patients (8/ 12 ), this pattern was reminiscent of periventricular leukomalacia. Focal white matter T2 hyperintensities were uncommon and mild.

Magnetic resonance spectroscopy. Mean Cho concentration was significantly lower in patients than in controls in the three regions examined (table 2).
Brain $\mathrm{Cr}$ and $\mathrm{Cho} / \mathrm{Cr}$ ratio were lower in patients than in controls, but these differences reached significance only for the Cho/ $\mathrm{Cr}$ ratio in the lenticular nuclei. In controls, Cho tended to decrease with age in frontal white matter and lenticular nuclei, whereas $\mathrm{Cr}$ decreased only in frontal white matter. In patients, both $\mathrm{Cho}$ and $\mathrm{Cho} / \mathrm{Cr}$ ratio decreased with age in each brain region examined (table e-2). The effect of age on Cho/Cr ratio clearly differed between cases and controls in frontal white matter $\left(p_{\text {interaction }}\right.$ $=0.0008)$ and thalami $\left(p_{\text {interaction }}=0.01\right)$. The $\mathrm{Cho/Cr}$ ratio decreased progressively with age in cases but was stable in controls (figure 2). We detected no differences between patients and controls in mean brain NAA concentrations nor any significant changes with age (tables 2 and e-2).

Biochemical studies. All patients had high plasma total homocysteine (table 3). Plasma methionine concentration was in the lower half of the distribution for all cases but, paradoxically, plasma AdoMet, the product of adenylation of methionine (figure 1, reaction C), was markedly increased in patients. AdoHcy, the product of all methyltransferases (figure 1 , reactions D and E), was also increased. Urine and plasma concentrations of guanidinoacetate, the precursor of creatine (figure 1, reaction D), were within reference range in all patients. Urinary excretion of creatine, the methylation product of guanidinoacetate, was significantly decreased. 


\begin{tabular}{|c|c|c|c|}
\hline Table 2 & $\begin{array}{l}\text { Brain NAA, Cho, and } \mathrm{Cr} \text { conce } \\
\text { by magnetic resonance spect }\end{array}$ & $\begin{array}{l}\mathrm{s}^{*} \text { and } \mathrm{Cho} / \mathrm{Cr} \text { ra } \\
\text { c imaging }\end{array}$ & sured \\
\hline Brain region & Patients $^{\dagger}, \mathrm{n}=9$ & Controls, $\mathrm{n}=36$ & $p$ Value $^{\ddagger}$ \\
\hline \multicolumn{4}{|c|}{ Frontal white matter } \\
\hline NAA & $0.220 \pm 0.045$ & $0.253 \pm 0.052$ & 0.1 \\
\hline Cho & $0.051 \pm 0.010$ & $0.064 \pm 0.010$ & 0.001 \\
\hline $\mathrm{Cr}$ & $0.142 \pm 0.027$ & $0.158 \pm 0.032$ & 0.1 \\
\hline $\mathrm{Cho} / \mathrm{Cr}$ & $0.380 \pm 0.108$ & $0.415 \pm 0.053$ & 0.2 \\
\hline \multicolumn{4}{|c|}{ Lenticular nucleus } \\
\hline NAA & $0.327 \pm 0.031$ & $0.347 \pm 0.032$ & 0.1 \\
\hline Cho & $0.056 \pm 0.011$ & $0.069 \pm 0.009$ & $<0.001$ \\
\hline $\mathrm{Cr}$ & $0.204 \pm 0.027$ & $0.213 \pm 0.022$ & 0.3 \\
\hline $\mathrm{Cho} / \mathrm{Cr}$ & $0.277 \pm 0.046$ & $0.331 \pm 0.053$ & $<0.01$ \\
\hline \multicolumn{4}{|l|}{ Thalamus } \\
\hline NAA & $0.328 \pm 0.051$ & $0.324 \pm 0.033$ & 0.8 \\
\hline Cho & $0.063 \pm 0.010$ & $0.071 \pm 0.007$ & 0.006 \\
\hline $\mathrm{Cr}$ & $0.163 \pm 0.017$ & $0.173 \pm 0.019$ & 0.2 \\
\hline $\mathrm{Cho} / \mathrm{Cr}$ & $0.388 \pm 0.056$ & $0.417 \pm 0.045$ & 0.1 \\
\hline
\end{tabular}

*LCModel untransformed concentrations; values are mean \pm SD.

${ }^{+}$Only the unrelated patients (including the proband of the family) were included in this anal$y$ sis to avoid overrepresentation of the three members of the same family.

${ }^{\ddagger} p$ values for differences between patients and control subjects using Student $t$ test.

$\mathrm{NAA}=\mathrm{N}$-acetylaspartate; $\mathrm{Cho}=$ water-soluble choline-containing compounds $\mathrm{Cr}=$ creatine.

DISCUSSION In agreement with most reports, RD patients in this study have a wide range of severe neurologic symptoms, including seizures, psychomotor delay, and cognitive impairment. The pathophysiologic mechanisms underlying the neurologic involvement in $\mathrm{RD}$ is not fully understood. Plasma homocysteine concentration is generally lower in $\mathrm{RD}$ than in CBS deficiency. However, in contrast to CBS deficiency, microcephaly is frequent in $\mathrm{RD}^{1}$ and was observed in six of our patients (table e-1). There is no obvious relationship between plasma homocysteine concentration and clinical phenotype.

Our hypothesis was that the lack of methyl groups could be responsible for secondary creatine deficiency and cerebral guanidinoacetate intoxication. By extension, transmethylation pathway disruption in RD may induce depletion of all AdoMetdependent biosynthetic processes. At least 50 AdoMet-dependent methylation reactions exist in mammals, which constitutes a minimal estimation as suggested by genomic analyses. ${ }^{13}$

MRSI was previously used to identify secondary brain creatine depletion in hyperornithinemia due to ornithine- $\delta$-aminotransferase deficiency, ${ }^{14}$ and it was hypothesized that the reduced brain creatine concentration contributed to the retinal degeneration observed in this condition. ${ }^{15}$ Six of our patients had retinitis pigmentosa or pigmentary maculopathy. In our study, we did not find significant brain creatine
Figure 2 Scatter plots of the choline/creatine ratio according to age in frontal white matter $(A)$, lenticular nuclei (B), and thalami (C)

A Frontal white matter

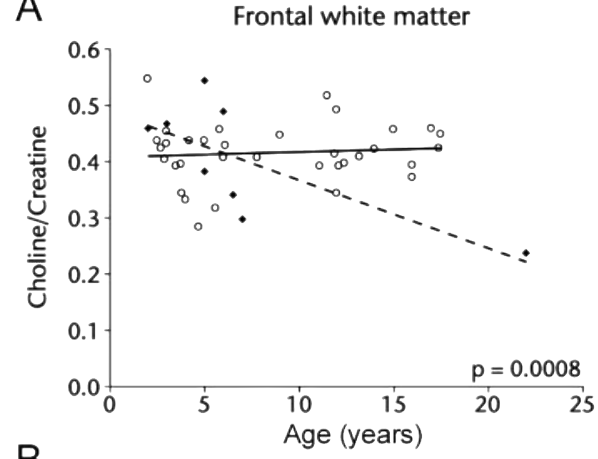

B

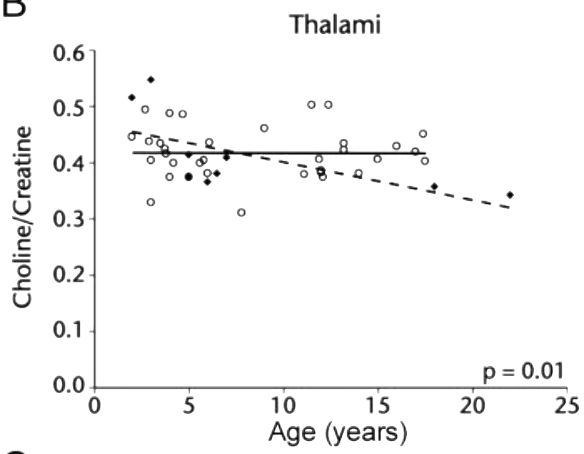

C Lenticular nuclei

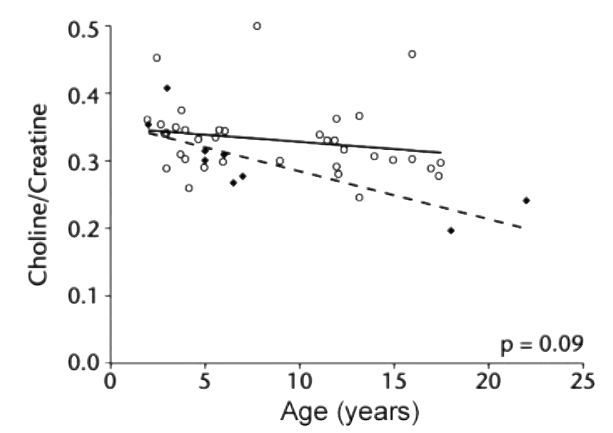

Solid lines are regression curves for patients ( $\downarrow$ ); dashed lines are regression curves for controls (०).

depletion, although given the small size of our sample, a definitive answer to this question will need further study. Low urinary creatine excretion indicates probable peripheral insufficiency, suggesting a compartmentation phenomenon. Moreover, no increase in guanidinoacetate concentration was found in plasma and urine, in contrast to a previous report on six CblC patients. ${ }^{16}$ Despite plasma creatine concentrations in the low-normal range, it is possible that brain creatine uptake was sufficient to sustain adequate brain creatine levels.

Based on early studies of the labile methyl balance, it has been considered that creatine biosynthesis consumed more AdoMet than all the other physiologic methyltransferases reactions combined, accounting for the use of more than $70 \%$ of AdoMet-derived methyl 


\begin{tabular}{|c|c|c|c|c|c|}
\hline \multirow{2}{*}{$\begin{array}{l}\text { Table } 3 \\
\text { Metabolite }\end{array}$} & \multicolumn{5}{|c|}{$\begin{array}{l}\text { Plasma and urine concentrations of transmethylation and creatine biosynthesis pathways } \\
\text { metabolites }\end{array}$} \\
\hline & & $\begin{array}{l}\text { Patients, } \\
\text { median } \\
\text { (range) }\end{array}$ & $\begin{array}{l}\%(95 \% \mathrm{Cl}) \\
\text { above/below limit } \\
\text { of reference } \\
\text { range* }^{*}\end{array}$ & $\begin{array}{l}\text { Reference } \\
\text { value }\end{array}$ & p Value ${ }^{+}$ \\
\hline \multicolumn{6}{|l|}{ Plasma } \\
\hline \multicolumn{2}{|c|}{ Homocysteine, $\mu \mathrm{mol} / \mathrm{L}$} & $72.3(42.5-151.5)$ & $100(72-100)$ & $5-15$ & $<0.001$ \\
\hline \multicolumn{2}{|c|}{ Methionine, $\mu \mathrm{mol} / \mathrm{L}$} & $13(11-23)$ & $0(0-28)$ & $9-37$ & NS \\
\hline \multicolumn{2}{|c|}{ AdoMet, nmol/L } & $250(60-379)$ & $90(60-98)$ & $65-125$ & $<0.005$ \\
\hline \multicolumn{2}{|c|}{ AdoHcy, nmol/L } & $35(19-46)$ & $90(60-98)$ & $4.9-19.7$ & $<0.001$ \\
\hline \multicolumn{2}{|c|}{ Creatine, $\mu \mathrm{mol} / \mathrm{L}$} & $23(8-57)$ & $0(0-28)$ & $6-109$ & NS \\
\hline \multicolumn{2}{|c|}{ Guanidinoacetate, $\mu \mathrm{mol} / \mathrm{L}$} & $1.4(1.1-1.9)$ & $0(0-28)$ & $0.35-3.5$ & NS \\
\hline \multicolumn{6}{|l|}{ Urine } \\
\hline \multicolumn{2}{|c|}{ Creatine, $\mathrm{mmol} / \mathrm{mol}$ creat } & $18(12-25)$ & $100(60-98)$ & $40-1,510$ & $<0.005$ \\
\hline \multicolumn{2}{|c|}{ Guanidinoacetate, $\mathrm{mmol} / \mathrm{mol}$ creat } & $52(22-107)$ & $0(0-28)$ & $18-159$ & NS \\
\hline
\end{tabular}

*For plasma homocysteine, S-adenosylmethionine (AdoMet), S-adenosylhomocysteine (AdoHcy), guanidinoacetate, and urine guanidinoacetate, we considered concentrations above the upper limit of the reference range. For plasma methionine, creatine, and urine creatine, we considered concentrations below the lower limit of the reference range. Only the unrelated patients (including the proband of the family) were included in this analysis to avoid overrepresentation of the three members of the same family.

${ }^{+} p$ value for comparison between patients and upper limit of the reference range (for homocysteine, AdoMet, AdoHcy, and guanidinoacetate) and the lower limit of the reference range (for methionine and creatine), using a one-sample signed rank test. NS $=$ not significant.

groups in humans. ${ }^{17,18}$ Recent studies in animal models as well as reexamination of the human creatine metabolism suggested that creatine synthesis was responsible for a smaller proportion of AdoMet-derived methyl group consumption and that phosphatidylcholine synthesis through the reaction catalyzed by the phosphatidylethanolamine methyltransferase was a major consumer of these methyl groups. ${ }^{19,20}$ In this study, we found that patients with RD had a significant decrease in choline-containing compounds signal in the brain. The Cho signal is mainly derived from the precursors of phosphatidylcholine, phosphocholine, free choline, and glycerophosphocholine. ${ }^{21}$ Overall, our results are in agreement with the recent estimation on the methyl group balance in humans. ${ }^{19,20}$ Phosphatidylethanolamine methyltransferase is the rate-limiting step of phosphatidylcholine synthesis in the liver. Its activity has also been specifically characterized in oligodendrocytes, although it was considered a minor contributor to the total phosphatidylcholine synthesis in the whole brain. Phosphatidylcholine synthesis in brain proceeds mainly through the CDP-choline/Kennedy pathway, directly incorporating phosphocholine on the diacylglycerol backbone. ${ }^{22}$ Nevertheless, conversion of phosphatidylethanolamine into phosphatidylcholine remains the only known pathway for the de novo choline biosynthesis in the body, ultimately supplying the brain in choline.

Of note, cerebral choline depletion observed by MRSI has been reported in an infant with dietary cobalamin deficiency ${ }^{23}$ and in a patient with
$S$-adenosylhomocysteine hydrolase deficiency ${ }^{24}$ (figure 1, reaction F), both situations potentially impairing transmethylation pathway. Because brain MRSI in patients with nonspecific psychomotor delay, myelination delay, or focal T2-weighted hyperintensities shows an increase in the choline signal, ${ }^{25-27}$ we think that our findings are specific to RD and related to the metabolic defects. In our patients, we can speculate that lifelong depletion of choline precursors has contributed to the periventricular white matter loss and cerebral atrophy observed on MRI.

Previous studies have shown that brain concentrations of creatine and choline remain constant after age 2 years. ${ }^{28}$ In our control group, we found a slight Cho decrease with age in frontal with matter and lenticular nuclei, whereas the $\mathrm{Cho/Cr}$ ratio was stable. By contrast, in patients, the $\mathrm{Cho} / \mathrm{Cr}$ ratio progressively decreased with age in the three brain regions examined. This suggests that brain Cho depletion occurs as an isolated phenomenon and that this deficiency seems persistent throughout life.

There was a paradoxical increase in plasma AdoMet in our patients, as previously reported in a study of six CblC patients. ${ }^{16}$ This was discordant with the concomitant low methionine levels. The explanation for such a paradoxical AdoMet increase remains unclear, but a secondary inhibition of the methylases is likely. This reintroduces a "toxic hypothesis" in the pathophysiologic model of the disease, in addition to the "depletion hypothesis" already discussed. AdoHcy, an inhibitor of many AdoMet-dependent methyltransferases, was high 
in our patients, but there was no significant association between AdoMet and AdoHcy concentrations. Of note, plasma AdoMet concentration was significantly higher in CblC patients than in MTHFR patients. Additional studies are needed to investigate the mechanisms underlying AdoMet accumulation in RD.

Our results show that patients with $\mathrm{RD}$ have an isolated deficiency of choline-containing compounds in the brain, probably due to the impairment of transmethylation processes. Paradoxical AdoMet increase suggests that secondary inhibition of methylases could contribute to the transmethylation defect in these conditions.

\section{ACKNOWLEDGMENT}

The authors thank Mrs. Yolande Lefevre for her excellent assistance during the course of this study and all patients and their families for their participation.

Received September 9, 2007. Accepted in final form March 7, 2008

\section{REFERENCES}

1. Rosenblatt DS, Fenton WA. Inherited disorders of folate and cobalamin transport and metabolism. In: Scriver CR, Beaudet AL, Sly WS, Valle D, eds. The Metabolic and Molecular Bases of Inherited Disease. 8th ed. New York: McGraw-Hill, 2001:3897-3933.

2. Rosenblatt DS, Aspler AL, Shevell MI, et al. Clinical heterogeneity and prognosis in combined methylmalonic aciduria and homocystinuria (cblC). J Inherit Metab Dis 1997;20:528-538.

3. Ogier de Baulny H, Gerard M, Saudubray JM, Zittoun J. Remethylation defects: guidelines for clinical diagnosis and treatment. Eur J Pediatr 1998;157:S77-S83.

4. Wyss M, Kaddurah-Daouk R. Creatine and creatinine metabolism. Physiol Rev 2000;80:1107-1213.

5. Clarke S, Banfield K. S-adenosylmethionine-dependent methyltransferases. In: Carmel R, Jacobsen DW, eds. Homocystine in Health and Disease. Cambridge, UK: Cambridge University Press, 2001:63-78.

6. Watkins D. Cobalamin metabolism in methioninedependent human tumor and leukemia cell lines. Clin Invest Med 1998;21:151-158.

7. Lerner-Ellis JP, Tirone JC, Pawelek PD, et al. Identification of the gene responsible for methylmalonic aciduria and homocystinuria, cblC type. Nat Genet 2006;38:93-100.

8. Provencher SW. Automatic quantitation of localized in vivo ${ }^{1} \mathrm{H}$ spectra with the LCModel. NMR Biomed 2001; 14:260-264.

9. Gellekink $H$, van Oppenraaij-Emmerzaal D, van Rooij A, Struys EA, den Heijer M, Blom HJ. Stable-isotope dilution liquid chromatography-electrospray injection tandem mass spectrometry method for fast, selective measurement of $S$-adenosylmethionine and $S$-adenosylhomocysteine in plasma. Clin Chem 2005;51:1487-1492.

10. Valongo C, Cardoso ML, Domingues $P$, et al. Age related reference values for urine creatine and guanidinoacetic acid concentration in children and adolescents by gas chromatography-mass spectrometry. Clin Chim Acta 2004;348:155-161.

11. Almeida LS, Verhoeven NM, Roos B, et al. Creatine and guanidinoacetate: diagnostic markers for inborn errors in creatine biosynthesis and transport. Mol Genet Metab 2004;82:214-219.

12. Newcombe RG, Altman DG. Proportions and their differences. In: Altman DJ, Machin D, Bryant TN, Gardner MJ, eds. Statistics with Confidence. London: BMJ Books, 2000:45-56.

13. Katz JE, Dlakic M, Clarke S. Automated identification of putative methyltransferases from genomic open reading frames. Mol Cell Proteomics 2003;2:525-540.

14. Näntö-Salonen K, Komu M, Lundbom N, et al. Reduced brain creatine in gyrate atrophy of the choroid and retina with hyperornithinemia. Neurology 1999; 53:303-307.

15. Sipila I, Rapola J, Simell O, Vannas A. Supplementary creatine as a treatment for gyrate atrophy of the choroid and retina. N Engl J Med 1981;304:867-870.

16. Bodamer OA, Sahoo T, Beaudet AL, et al. Creatine metabolism in combined methylmalonic aciduria and homocystinuria. Ann Neurol 2005;57:557-560.

17. Mudd SH, Poole JR. Labile methyl balances for normal humans on various dietary regimens. Metabolism 1975; 24:721-735.

18. Mudd SH, Ebert MH, Scriver CR. Labile methyl group balances in the human: the role of sarcosine. Metabolism 1980;29:707-720.

19. Noga AA, Stead LM, Zhao Y, Brosnan ME, Brosnan JT, Vance DE. Plasma homocysteine is regulated by phospholipid methylation. J Biol Chem 2003;278:5952-5955.

20. Stead LM, Brosnan JT, Brosnan ME, Vance DE, Jacobs RL. Is it time to reevaluate methyl balance in humans? Am J Clin Nutr 2006;83:5-10.

21. Boulanger Y, Labelle M, Khiat A. Role of phospholipase $\mathrm{A}_{2}$ on the variation of the choline signal intensity observed by ${ }^{1} \mathrm{H}$ magnetic resonance spectroscopy in brain diseases. Brain Res Rev 2000;33:380-389.

22. Vos JP, de Haas CGM, van Golde LMG, Lopes-Cardozo M. Relationships between phosphatidylcholine, phosphatidylethanolamine and sphingomyelin metabolism in cultured oligodendrocytes. J Neurochem 1997;68:1252-1260.

23. Horstmann M, Neumaier-Probst E, Lukacs Z, Steinfeld R, Ullrich K, Kohlschutter A. Infantile cobalamin deficiency with cerebral lactate accumulation and sustained choline depletion. Neuropediatrics 2003;34:261-264.

24. Baric I, Fumic K, Glenn B, et al. S-adenosylhomocysteine hydrolase deficiency in a human: a genetic disorder of methionine metabolism. Proc Natl Acad Sci USA 2004;101: 4234-4239.

25. Kreis R, Ernst T, Ross BD. Development of the human brain: in vivo quantification of metabolite and water content with proton magnetic resonance spectroscopy. Magn Reson Med 1993;30:424-437.

26. Yeo RA, Hill D, Campbell R, Vigil J, Brooks WM. Developmental instability and working memory ability in children: a magnetic resonance spectroscopy investigation. Dev Neuropsychol 2000;17:143-159.

27. Filippi CG, Ulug AM, Deck MD, Zimmerman RD, Heier LA. Developmental delay in children: assessment with proton MR spectroscopy. AJNR Am J Neuroradiol 2002;23:882-888.

28. Pouwels PJW, Brockmann K, Kruse B, et al. Regional age dependence of human brain metabolites from infancy to adulthood as detected by quantitative localized proton MRS. Pediatr Res 1999;46:474-485. 
Reduced brain choline in homocystinuria due to remethylation defects

F. -G. Debray, Y. Boulanger, A. Khiat, J. -C. Decarie, J. Orquin, M. -S. Roy, A. Lortie, F. Ramos, N. M. Verhoeven, E. Struys, H. J. Blom, C. Jakobs, E. Levy, G. A. Mitchell and M. Lambert

Neurology 2008;71;44-49

DOI: 10.1212/01.wnl.0000316391.40236.c3

This information is current as of January 30, 2009

\begin{tabular}{|ll|}
\hline $\begin{array}{l}\text { Updated Information } \\
\text { \& Services }\end{array}$ & $\begin{array}{l}\text { including high-resolution figures, can be found at: } \\
\text { http://www.neurology.org/cgi/content/full/71/1/44 }\end{array}$ \\
Supplementary Material & Supplementary material can be found at: \\
http://www.neurology.org/cgi/content/full/71/1/44/DC1 & This article, along with others on similar topics, appears in the \\
& following collection(s): \\
& MRS \\
http://www.neurology.org/cgi/collection/mrs Metabolic disease \\
(inherited) \\
http://www.neurology.org/cgi/collection/metabolic_disease_inherit \\
ed Amino acid \\
http://www.neurology.org/cgi/collection/amino_acid All Pediatric \\
http://www.neurology.org/cgi/collection/all_pediatric All Genetics \\
http://www.neurology.org/cgi/collection/all_genetics \\
Information about reproducing this article in parts (figures, tables) \\
or in its entirety can be found online at: \\
http://www.neurology.org/misc/Permissions.shtml \\
Information about ordering reprints can be found online: \\
http://www.neurology.org/misc/reprints.shtml
\end{tabular}

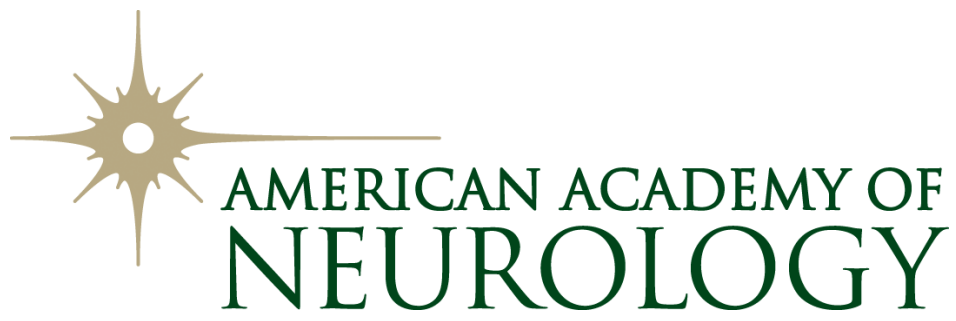

